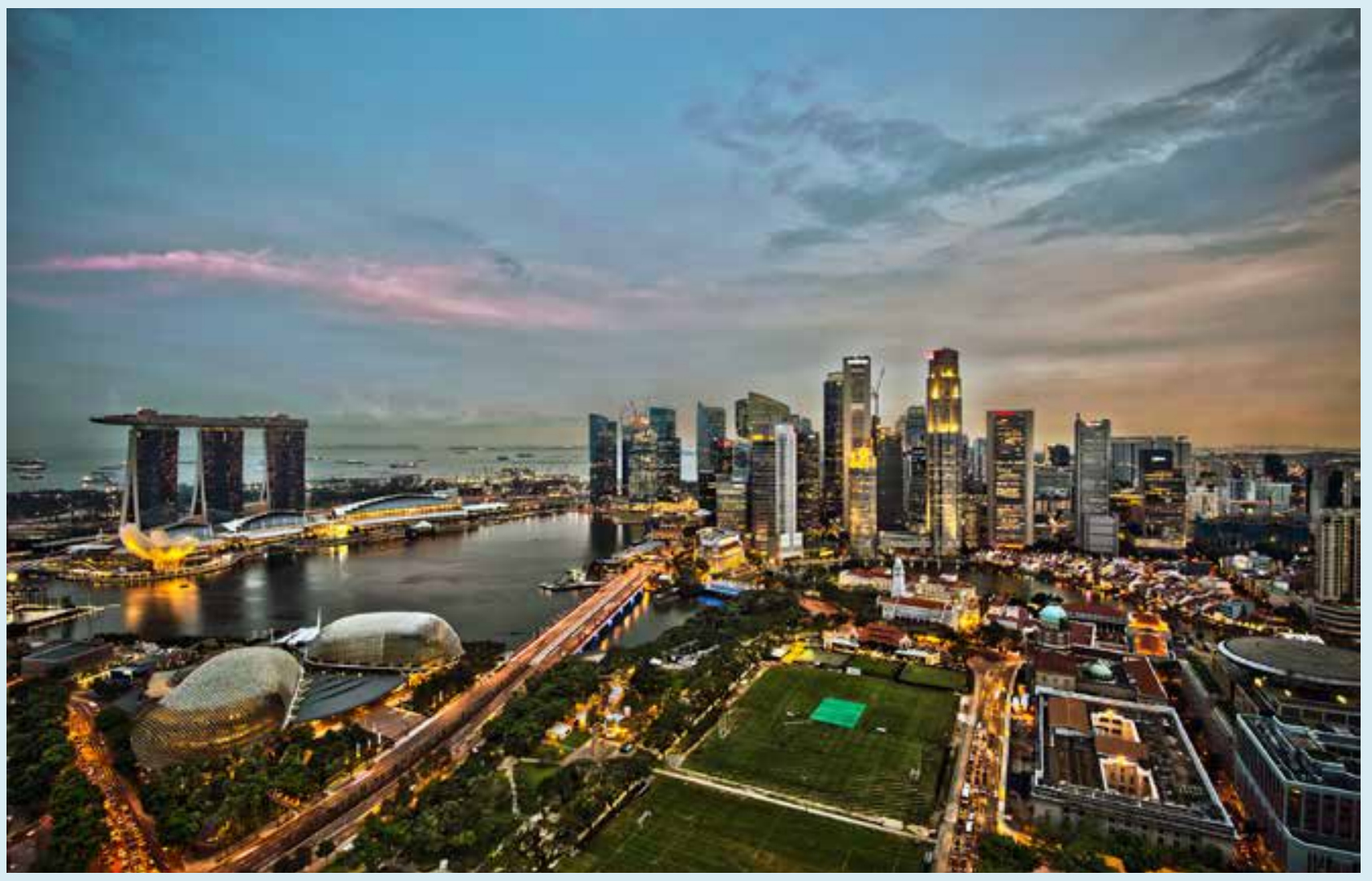

FIG 1 Singapur, establecida como Zona de Libre Comercio en 1969 /

Singapore, established as Free Trade Zone in 1969. (c) Chensiyuan

\title{
ZONES
}

\section{OF ECONOMIC EXCEPTION}




\title{
Keller Easterling
}

\author{
Profesora, Escuela de Arquitectura de Yale \\ Universidad de Yale, New Haven, CT \\ Estados Unidos \\ Entrevistada por / Interviewed by \\ Francisco Díaz
}

The 'zones' -parts of territory that have an exceptional legal status- are sharply depicted in Keller Easterling's recent book Extrastatecraft: the power of infrastructure space. Explaining that zones are repeatable spatial formulas used by the most powerful people in the world (so they have huge political consequences), in this interview Easterling also provides a series of arguments for why architects should not ignore these kinds of spatial products.

KEYWORDS - capital, urbanism, active form, exemption, incentives

FRANCISCO DíAZ: I'd like to start by asking you about the relationship between exception and exemption you observed in Enduring Innocence: Global Architecture and its Political Masquerades (FIG. 2). Tax exemptions in certain urban areas generate urban zones of exception where development is promoted through an urbanism that "has become addicted to incentives" (2005:133). Then, in Extrastatecraft: The Power of Infrastructure Space (FIG.3) you studied these zones more in depth. How and why did you start observing these phenomena?

KELLER EASTERLING: In my previous book, Enduring Innocence, I was looking at spatial products around the world, and I began to notice that not only had franchises, resorts and retail become repeatable spatial products, but also whole cities. Studies of the zone were therefore an extension of these studies. I had been looking at spatial products that could territorialize huge areas of land like the greenhouse agropole or the automated port so that led quite naturally to the study of the zone in the book Extrastatecraft.

As an architect, does your interest in these topics come from their relation to space?

Spatial products were designed to be apolitical. Enduring Innocence demonstrated the ways in which they landed right in the crosshairs of political conflict, or political consequence. So here were spaces that architects typically ignore that were 


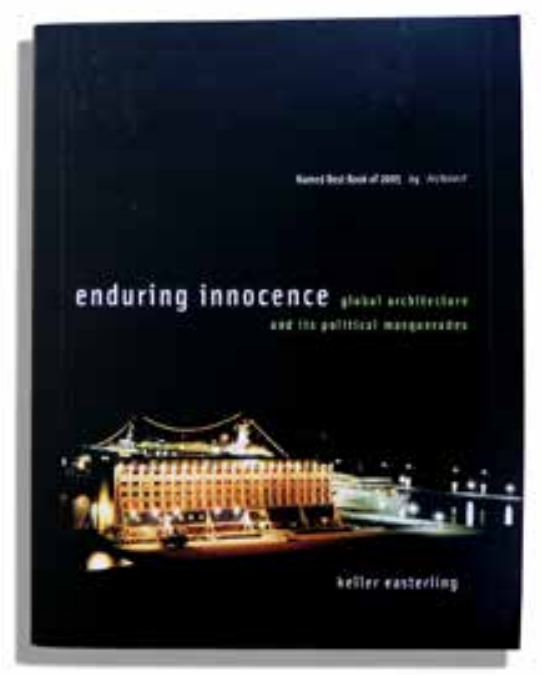

FIG 2 Keller Easterling. Enduring innocence, global architecture and its political masquerades (2006)
Keller Easueting

Ex tra

Exwsta

craft $\square: \square$

Them

Pow waer =a

of 国infara

strucereture

sparaces

FIG 3 Keller Easterling. Extrastatecraft: The power

of infrastructure space (2014)

becoming powerful political pawns in the world. In this most recent book, I have characterized these mega-spatial products, like the free zone, as perfect vessels of "extrastatecraft." I am arguing that these spaces bring to our art -our work as architects- another relevance.

These zones of economic exception have become 'architectural paradises' where capital invests in signature architecture -"the symbolic capital of a shiny skyline" (2014:160)- as in Dubai, Singapore, Ordos or Shenzhen, to name a few. What would the relationship be between signature architecture and tax exemption?

Well, it's tricky. Zones allow for foreign ownership of property, so foreign investment in a zone may or may not be the reason for a new building. But during the last thirty to forty year period of rapid zone growth, there is another stranger phenomenon. As the zone has mutated from warehousing compounds for storing custom free trade to a glittering skyline, that glittering skyline became a kind of symbol of entry into the global market.

We can also look at foreign ownership of property and Islamic Banking that have made the zone into a bit of a 'real estate casino.' One might be investing in buildings to hold money, because real estate investments, unlike some interest-providing banking products, are allowed in Islamic Banking. That may be another reason for the explosion of signature architecture buildings in the shiny skyline.

And you mentioned the difference between exemption and exception before, and there is a difference between Agamben's very particular argument about exception and the exemptions found in the zone. Given the multiple forms of exemptions offered to many countries, in the zone there are overlapping sets of 
exceptions that are maybe harder to trace. There are multiple exceptions that are perhaps more treacherous because they are harder to identify or target.

In Extrastatecraft you tell the history of the EPZ -Export Processing Zone- a formula created and promoted by the United Nations. Is an extrastate organization like the UN a tool or device to create exceptions across the world?

The UN had noticed some experiments already undertaken by the United States and others, so they didn't really invent the idea of the EPZ, but they took a formula that was already in play (e.g. Puerto Rico, Shannon, Ireland) and began to promote it to developing countries as a way to enter the global market.

By the eighties, the World Bank and other institutions found that the zone was a suboptimal economic instrument, but by then it had become a self-fulfilling prophecy.

One can give a sinister twist to this privileging of western corporate investment with its paternal attitude towards developing countries. It's as if developing countries should tailor their offerings to western corporations, and corporations should be able to characterize their investment as a 'helping hand' to developing countries.

Well, we know that very well in Chile... But turning the question back to cities. You have said "cities gamble with exceptional conditions" (2005:134). However, today the zone seems to grow -including new programs and facilities- until becoming a city in itself. I'd like to have your thoughts on this: will the zone replace the city?

Cities -or at least the cities we value- often invite contradiction and diversity. The zone does not do that. The zone is usually a closed loop; and while it is really the opposite of the city, zones now often call themselves 'cities.' Sometimes they are as big as cities, and they have a range of programs like one would see in a city. I've claimed that in some ways the zone formula is the infrastructural technology with which the world now makes cities, so in a way the zone has already made a series of citiesShenzhen is a city (FIG.4), Dubai is a city-state (FIG.5).

The zone formula has mutated so rapidly over the last thirty years, often being based on all kinds of irrational desires. Therefore I keep wondering if we might take advantage of the zone's desire to be a city. Might we sort of trick the zone with other persuasions and desires that begin to introduce the protections, the contradictions, the differences and the circumstances that we often praise in urbanity.

But if the zone is a sort of new way of making cities it means it's no longer exceptional; and if the zone is not an exception and becomes normal, then it shouldn't be different from the city.

Yes, but it has a different legal status than a city. For instance, if you are in a city, it may be legal to have labor unions, but if you 


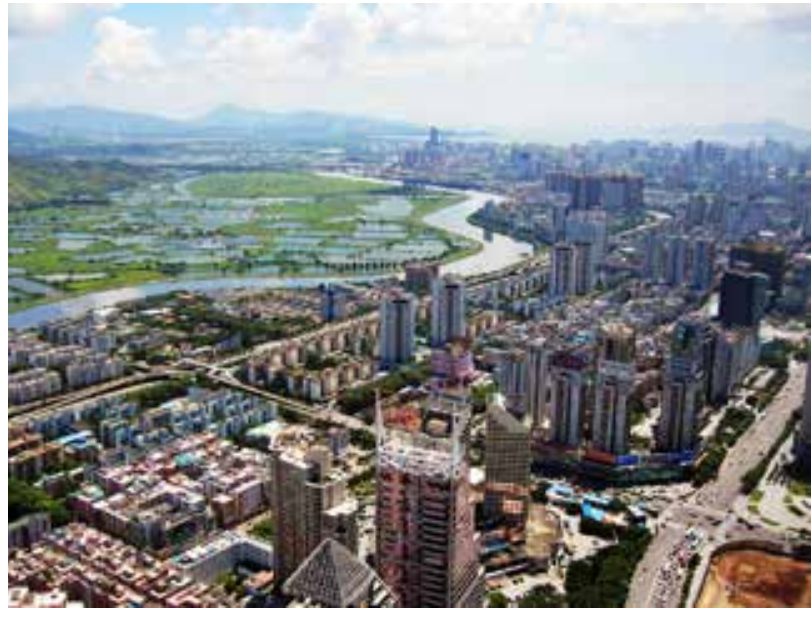

FIG 4 Shenzhen, China. Zona económica especial desde 1979 / Special Economic Zone since 1979. (C) SSDPenguin

\section{“...many major cities, even national capitals, want to have their own zone, doppelganger, or shadow. In some ways it is the shiny new version of the city that can do all the dirty work that the city can't do."}

are in a free zone, it's often impossible to have a labor union. That's just an example. It's the selected exemptions from laws that make these ex-urban enclaves dangerous in my view.

So there are different kinds of zones, and they depend on the regulations that each zone is exempted from.

Cities sometimes offer exemptions of different kinds like tax holidays. This is an ordinary thing that any city might do. However, it is important to balance what is being given away with what is being gained especially when the trade involves oversight of labor or rights of citizens. One can recognize that foreign direct investment is sometimes necessary for jobs and so on, but that investment can be positioned to make a better bargain for the host country. It can also be located in existing cities rather than in ex-urban enclaves. I'm not saying that this is a solution, but I would argue that, in existing cities, it's possible to make better bargains with these incentives while protecting citizens and returning more economic benefits directly to the host country. The zone often obstructs these advantages, and so it is a pretty dumb form.

Among the characteristics of the zone that you discovered there is this idea of the zone as a 'double' of an existing city, and I would like to relate this idea to large companies. Companies have a public face -a brand, a logo, headquarters, a charismatic CEO perhaps, advertisement and so on- but they also have a backstage, a sort of 'dark side of the moon' that we do not see. Following your idea of the zone as a 'double', can the zone be just the dark side of the moon-the negative instead of the double?

I completely agree. It's a shadow. It's a pirate. So many major cities, even national capitals, want to have their own zone, doppelganger, or shadow. In some ways it is the shiny new version of the city that can do all the dirty work that the city can't do. It's very much like the Queen sending out a pirate with a letter of marque, to do a special kind of job. The city and the zone use each other -and I am quoting from the book- as "brand" or "proxy" or "camouflage." 


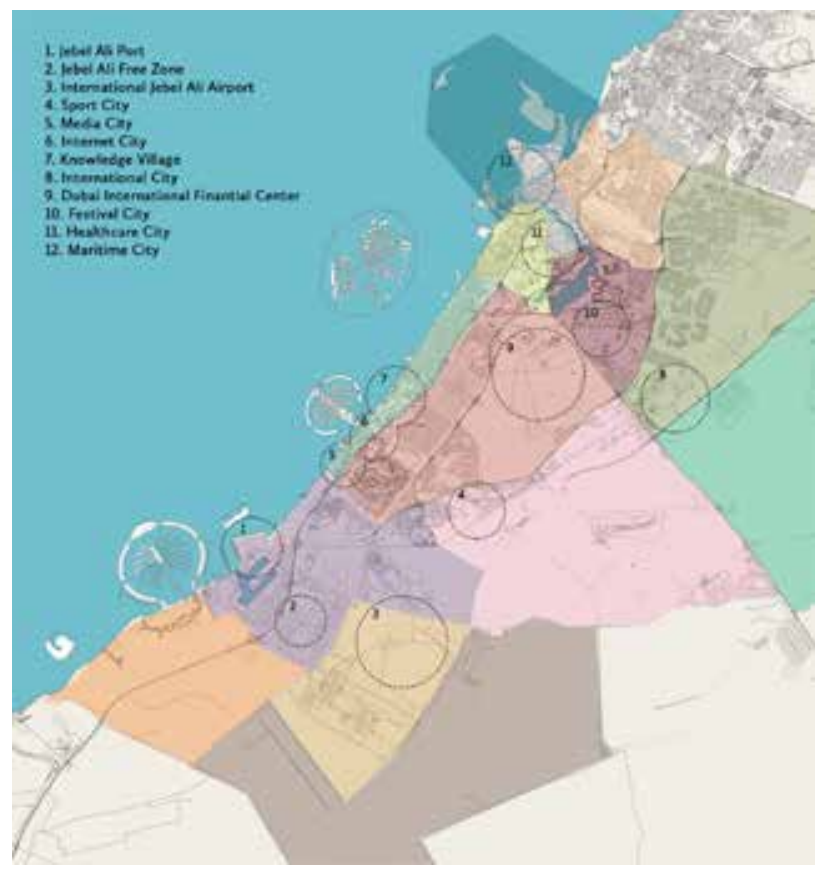

FIG 5 Dubai. Mapa de zonas / Zone map. (C) ARQ

Another argument that you propose for this is to understand the zone as a tool that cities use to 'launder identity', as a sort of 'ticket into the global market'. However, we know that what is successful in one case might not be so in another. Furthermore, successful cases are indeed exceptions-think for instance of all the cities that have unsuccessfully tried to replicate the Guggenheim effect. What if instead of a ticket into a global market the zone were just a sort of pyramidal scam?

Yes. The zone is a bit of a confidence game, or a pyramid scheme if you will.

I collect a lot of promotional videos of zones where you see these fantastic projections, almost fairy tale projections of building shapes like diamonds, dolphins and crystals (FIG.6). It's kind of a confidence game to lure in foreign investment even before the thing exists. Many of them fail to surface or fail to get all the investment that they need, and as these ideas become more contagious, they are accompanied by more and more delirious imagery.

There have been failures and scams. I often show a promotional video for a proposed city named Lazika, which was supposed to be built on a swamp area of the Black Sea (FIG.7). It would have required 80 -foot piles just to reach the bedrock on which the mirrored skyline would be built; and against every rational calculation, you see countries wagering for that shiny, mirrored kind of skyline at any cost.

However, it is good news in a way since all this is often based on desire rather than cast iron economic logics. 


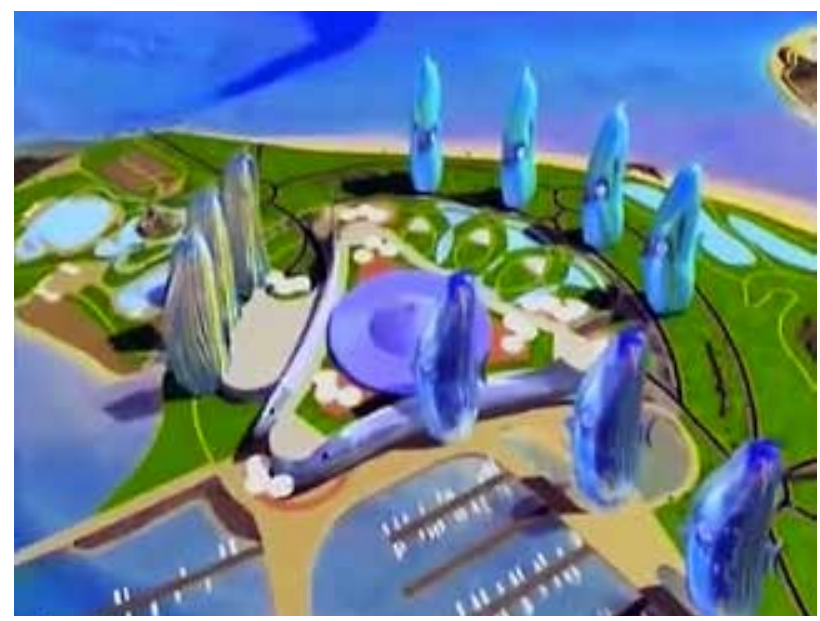

FIG 6 Tunisia Economic city, Tunisia. Edificios con forma de delfines / Dolphin shaped buildings. Captura del film: / Frame taken from the film: Keller Easterling, «World City Trailers» (2014). https://vimeo.com/112833164

What is interesting about the pyramidal scheme is that in order to have a winner you need a lot of losers, and losers are the structure for the scam.

Yes, and the other thing that makes it a little like the pyramid scheme is that the zone formula is always promoted to the next poorest country. The next poorest country wants it because all the other ones have it. And if your country has $40 \%$ unemployment, how can you say, 'wait a minute, this is not for us'? How can you say no when the other people in the pyramid will say yes? So it's successful because it's successful, it's popular because it's popular...

If one follows the argument you develop in Extrastatecraft, zones seem to be like valves that activate the potential energy of capital, as if capital were full of potential without any chance to unleash it until a zone appears. Would you say that capital's potential energy could decrease without these zones?

The zone is not some kind of perfect formula. It looks like the perfect island of corporate externalizing, in the sense that it tries to eliminate all obstacles to profit, but I'm arguing that there are different kinds of situations in which both urban environment and capital could win. There are reasons why capital has succeeded in large, diverse cities, so the need for greenfield development and a political tabula rasa or a political quarantine is just a myth; and there are also many reasons why the interplay that is natural to cities could be beneficial for both cities and for capital.

Do you have an example of a city that has worked well for instance in a developing country- without exemptions in its regulations? 


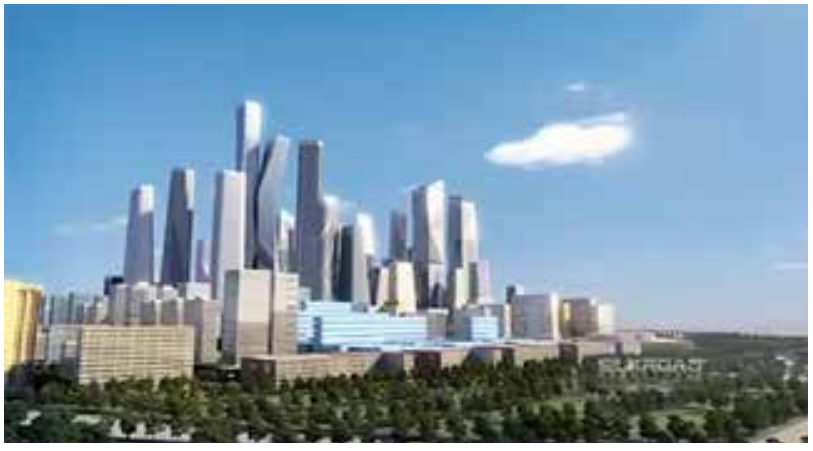

FIG 7 Lazika, Georgia. Captura del film: / Frame taken from the film: Keller Easterling, «World City Trailers» (2014). https://vimeo.com/112833164

\section{"There are many reasons why capital has succeeded in large, diverse cities, so the need for greenfield development and a political tabula rasa or a political quarantine is just a myth."}

I think you can see the reasons why major corporations wanted their headquarters in major cities around the world, and sometimes the zones try to mimic that; but they never provide the kind of diversity that you find in major cities. Although I don't have an example of a successful 'anti-zone' that is being deployed, if you look at a city like Nairobi (FIG. 8), you see the ways in which a zone incentive may be placed in interplay with all kinds of other things that the city needs.

When Dubai was inviting foreign investors, they said "Ok, if you want to invest in the oil and gas industry that's fine, but you also have to invest in industry that we want: fish farming, desalination, aluminum, tourism". They basically made a better bargain with their resources and with the foreign investment. They made demands that leveraged something better. Why can't a city like Nairobi do the same thing? Why must it follow this outdated formula of the zone, as if the zone were the only possible fertile ground for capital? Incentives might be offered to capital but placed in some kind of interdependent relationship that leverages something that Nairobi needs-something like transport for instance; and that transport would do a better job of delivering workers to the businesses in question. Therefore, there can be mutual advantages for both capital and for the host country. It's just completely unimaginative to assume that there is only one option for organizing investment.

Changing the subject, you have compared architecture with stones in a stream: the stone is visible but can do nothing to prevent the stream from flowing. However, would it be possible to understand the stone in relation to the stream if there were no stream? More precisely, in the case of architecture, can there be an object if there are no flows?

I was trying to talk about our ability to make both object form and active form, and I was saying that we might be good at both: making the stone and making the water. At work in the world today there are some very powerful kinds of form that involve all of our fundamental skills, but they don't necessarily behave like object form. These are forms that are not necessarily assessed for shape, geometry, or outline like an object. They are active forms that are less like stones and more like water.

In the book Extrastatecraft this is explained and explored in depth. The reader is invited to think about how we could 


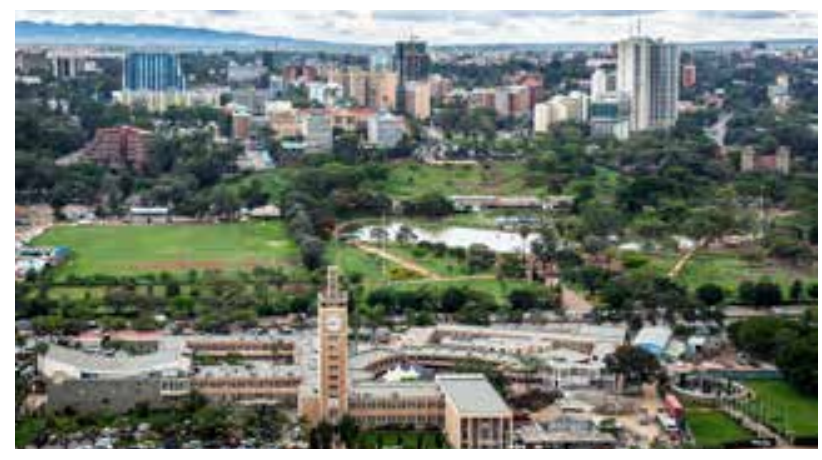

FIG 8 Nairobi, Kenya. (c) Ninara

design and adjust this consequential form. This kind of matrix space is making repeatable formulas for space and cities all around the world. It's something more like software, or something more like a kind of operating system.

Therefore l've been saying: wouldn't it be amazing if we were good at active form-like the little bits of code in the software that determine how objects will be multiplied and circulated? Active form redoubles our powers. At the moment, it may even be harder to make meaningful object form in the world's matrix space. This matrix space of repeatable formulas is the secret weapon of the most powerful people on earth, and it shouldn't be a secret best kept from those of us who are trained to make space. This is what we do. We can do amazing things, with enormous political consequence. At least this is my very hopeful argument.

Finally, events like the recent attacks in Paris or the shootings in different cities of the United States usually have militarization of everyday life as a response. In those cases the city becomes a place where law is interrupted through curfew, surveillance, shortage of liberties and so on. You have noted how corporations used the war "like a valve that could be turned on and off to create profits from currency differentials" (2014:151). Do you think that today's militarization of life is part of that process? What if the zone that creates profit is no longer a trade zone but rather a war zone?

There are people who are arguing that. I'm thinking of someone like Stephen Graham who has been amazing in his descriptions of 'securitization'. You could look at the zone with its security fence, its security checkpoint at the gate and so on, as a form of securitization.

Still, because there are people like Stephen Graham doing such a good job, I wonder if we might move beyond automatic associations with military, to look at other forms of violence that exist within the zone. Sometimes the automatic association with the military -or the pyrotechnics of the military- prevents us from seeing some of the other low level forms of constant, everyday violence. This is violence largely endured by labor. 


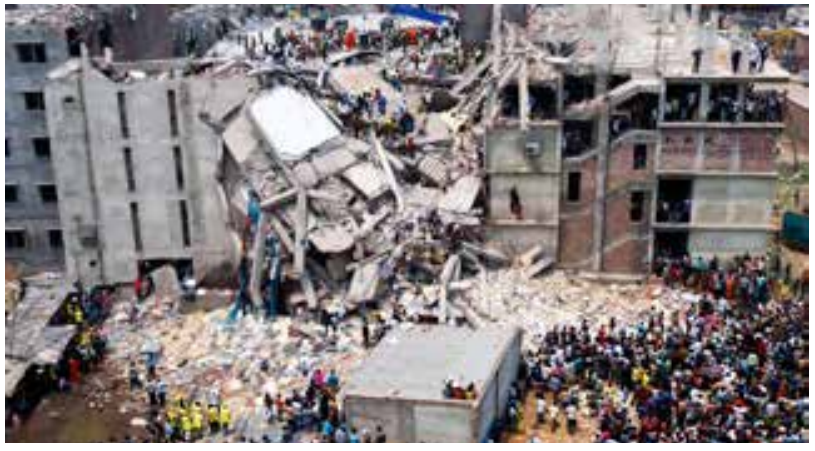

FIG 9 Dhaka Savar Building (Rana Plaza, Savar) Tras su colapso / After its collapse. (C) Rijans (13.05.2013)
Think of Rana Plaza in Bangladesh-the worst industrial disaster in human history (FIG.9). We didn't pay attention to the gradual attrition that caused that disaster. We only paid attention when it looked like an explosion of war. However its cause was the kind of violence that is immanent in the closed loop of the zone, in the denial of information. Therefore in this book Extrastatecraft I'm trying to put the reader's hands on the faders and toggles of power in matrix space, so that we can get a feel for markers of violent dispositions in space. What is breeding the violence that is confounding the world at the moment? What's in our suburbs or in our communities that allows that kind of violence to exist? You can no longer say that this is just on the battleground. It is really everywhere now, this kind of atomized violence.

Extrastatecraft is literally thinking about what changes to space reduce violence. When is violence immanent in an arrangement or disposition of space? How can we be attuned to that? We can do more than simply assess spaces for the way that they look, for their shape and outline. It may not be everyone's artistic choice, but we can extend our powers as designers to manipulate the political disposition of some of the world's most consequential spaces. ARQ

BIBLIOGRAFÍA / BIBLIOGRAPHY

EAST E R LING, Keller. Extrastatecraft: the power of infrastructure space. London; Brooklyn, NY: Verso, 2014.

E A S T E R LING, Keller. Enduring innocence: global architecture and its political masquerades. Cambridge, Mass.: M1T Press, 2005.

GRAH AM, Stephen. Cities under siege: the new military urbanism. London; Brooklyn, NY: Verso, 2 oIo.

KELLER EASTERLING

$<$ keller.easterling@yale.edu>

Architect, writer and professor at Yale University. She has written the books Extrastatecraft: The Power of Infrastructure Space (Verso, 2014), Subtraction (Sternberg Press, 2014), The Action is the Form: Victor Hugo's TED Talk (Strelka Press ebook, 2012), Enduring Innocence: Global Architecture and its Political Masquerades (MIT Press, 2005) and Organization Space: Landscapes, Highways and Houses in America (MIT Press, 1999). Easterling's research and writing was included in the 2014 Venice Biennale, and she has been exhibited at Storefront for Art and Architecture in New York, the Rotterdam Biennale, and the Architectural League in New York. Easterling has lectured and published widely in the United States and abroad. The journals to which she has contributed include Domus, Artforum, Grey Room, Cabinet, Volume, Assemblage, e-flux, Log, Praxis, Harvard Design Magazine, Perspecta, and ANY. 